\title{
Nine susceptibility loci for hepatitis B virus-related hepatocellular carcinoma identified by a pilot two-stage genome-wide association study
}

\author{
LI-SHUAI QU ${ }^{1 *}$, FEI JIN ${ }^{2 *}$, YAN-MEI GUO ${ }^{3}$, TAO-TAO LIU ${ }^{3}$, RU-YI XUE $^{3}$, XIAO-WU HUANG ${ }^{4}$, \\ MIN XU ${ }^{4}$, TAO-YANG CHEN ${ }^{5}$, ZHENG-PING NI ${ }^{5}$ and XI-ZHONG SHEN ${ }^{3}$
}

\author{
${ }^{1}$ Department of Gastroenterology, Affiliated Hospital of Nantong University, Nantong, Jiangsu 226001; \\ ${ }^{2}$ Department of Gastroenterology, Shanghai Xuhui Central Hospital, Shanghai; ${ }^{3}$ Department of Gastroenterology, \\ Zhongshan Hospital; ${ }^{4}$ Department of Liver Surgery, Liver Cancer Institute, Zhongshan Hospital, Fudan University, \\ Shanghai 200032; ${ }^{5}$ Department of Liver Surgery, Qidong Liver Cancer Institute, Qidong, Jiangsu 226200, P.R. China
}

Received November 16, 2014; Accepted October 26, 2015

DOI: $10.3892 / \mathrm{ol} .2015 .3958$

\begin{abstract}
Previous studies have indicated that complex interactions among viral, environmental and genetic factors lead to hepatocellular carcinoma (HCC). To identify susceptibility alleles for hepatitis B virus (HBV)-related HCC, the present study conducted a pilot two-phase genome-wide association study (GWAS) in 660 Han Chinese individuals. In phase 1, a total of 500,447 single-nucleotide polymorphisms (SNPs) were genotyped in $50 \mathrm{HCC}$ cases and 50 controls using Affymetrix GeneChip 500k Array Set. In phase 2, 1,152 SNPs were selected from phase 1 and genotyped in 282 cases and 278 controls using the Illumina GoldenGate platform. The prior probability of HCC in control subjects was assigned at 0.01 , and false-positive report probability (FPRP) was utilized to evaluate the statistical significance. In phase 1 , one SNP (rs2212522) showed a significant association with HCC $\left(\mathrm{P}_{\text {allele }}=5.23 \times 10^{-8} ; \mathrm{OR}_{\text {allele }}=4.96 ; 95 \% \mathrm{CI}, 2.72-9.03\right)$. In phase 2, among 27 SNPs with unadjusted $\mathrm{P}_{\text {allele }}<0.05,9$ SNPs were associated with HCC based on FPRP criteria (FPRP <0.20). The strongest statistical evidence for an association signal was with rs2120243 (combined OR $_{\text {allele }}=1.76$; 95\% CI, 1.39-2.22; $\mathrm{P}=2.00 \times 10^{-6}$ ), which maps within the fourth intron of VEPH1. The second strongest statistical evidence for an association was identified for rs 1350171 (combined $\mathrm{OR}_{\text {allele }}=1.66 ; 95 \% \mathrm{CI}$, 1.33-2.07; $\mathrm{P}=6.48 \times 10^{-6}$ ), which maps to the region downstream of the FZD4 gene. The other potential susceptibility genes
\end{abstract}

Correspondence to: Professor Xi-Zhong Shen, Department of Gastroenterology, Zhongshan Hospital, Fudan University, 180 Fenglin Road, Shanghai 200032, P.R. China

E-mail: shenxizhong@126.com

*Contributed equally

Key words: single-nucleotide polymorphisms, hepatitis B virus, hepatocellular carcinoma included PCDH9, PRMT6, LHX1, KIF2B and L3MBTL4. In conclusion, this pilot two-phase GWAS provides the evidence for the existence of common susceptibility loci for HCC. These genes involved various signaling pathways, including those associated with transforming growth factor $\beta$, insulin/phosphoinositide 3 kinase, Wnt and epidermal growth factor receptor. These associations must be replicated and validated in larger studies.

\section{Introduction}

Hepatocellular carcinoma (HCC) is the fifth most common cancer worldwide and the third leading cause of cancer-related mortality (1). In recent years, the incidence of HCC in western countries has increased markedly (2). HCC has a number of notable epidemiological features, including marked variations between geographical regions, racial and ethnic groups, and genders. Previous studies revealed that men have a higher prevalence of HCC than women; the ratio of affected men to affected women varies between 2:1 and 4:1 (3). In high-risk Chinese populations, the male:female ratio of HCC patients is 2.65:1 (2). HCC frequently occurs within an established background of chronic liver disease and cirrhosis. Major causes of cirrhosis in patients with HCC include hepatitis B virus (HBV) and hepatitis $\mathrm{C}$ virus (HCV), alcoholic liver disease and, possibly, non-alcoholic steatohepatitis $(3,4)$. China has a high incidence of $\mathrm{HCC}$, and the newly diagnosed $\mathrm{HCC}$ patients in China account for $~ 55 \%$ of the newly diagnosed HCC patients globally each year (5). HBV infection is one major risk factor for HCC occurrence; $\geq 75 \%$ cases of HCC are associated with HBV infection in China (6). However, not all individuals in $\mathrm{HBV}$-infected populations develop HCC over their lifetime. This phenomenon indicates that an individual's genetic background is important in HBV-related hepatocarcinogenesis (3).

To date, the predominant strategy employed to investigate $\mathrm{HCC}$-associated genes has been the candidate gene-based case-control association study. The candidate genes have included GSTT1, GSTM1, UGT1A7, CYPs, NAT2, HFE, MTHFR, TGF $\beta, T N F \alpha$ and MnSOD (7-11). By reviewing 
these studies, we observed numerous inconsistent results, and the associations reported were based on strong evidence. As the molecular mechanisms of most complex diseases, including $\mathrm{HCC}$, are still unknown, the candidate strategy has inherent limitations; in fact, it is a process of validation of the equivocal hypothesis and the conclusions of such studies should also be drawn cautiously. Based on the success of the human genome project, the HapMap Project, and the availability of high throughput gene chips, the whole genome-wide association study (GWAS) has become the most powerful approach to search for and map the susceptibility genes of complex diseases $(12,13)$. Since 2005, GWAS has achieved great success in identifying susceptibility genes in complex diseases, including diabetes $(14)$, cancer $(15,16)$ and systemic lupus erythematosus (17). Recently, a GWAS conducted in China reported 1p36.22 as a novel susceptibility locus for HCC (18).

Distinct clinical characteristics of HBV infection have been reported in different geographical regions of the world, and increasing evidence indicates an association with the genetic diversity of infected patients $(19,20)$. However, such data are largely lacking in Qidong, China, where chronic HBV infection is highly endemic (21). In the present study, a pilot two-stage GWAS was conducted to search for susceptibility loci for HCC. In order to maximize the statistical power to identify associations, homogeneity of the samples was ensured by selecting participants from the male Chinese Han population with $\mathrm{HBV}$ surface antigen (HBsAg) seropositivity, and a high proportion of HCC cases with a family history of HCC was included.

\section{Materials and methods}

Participants. The present analysis used data and stored samples from a prospective cohort in Qidong, Jiangsu, China. The enrollment of the study cohort has been previously described (22-24). Briefly, male HCC patients with $\mathrm{HBsAg}$ seropositivity were recruited from inpatients at the Qidong Liver Cancer Institute (Qidong, China), between August 1, 2006 and July 31, 2008. HCC was diagnosed by histopathological biopsy, or by elevated $\alpha$-fetoprotein (AFP) levels and distinct changes on imaging (ultrasonography, computed tomography and magnetic resonance imaging), according to the 2004 Barcelona guidelines (25). Blood samples were collected at the time of HCC diagnosis. All male control subjects were selected from a cohort consisting of HBsAg carriers, established by Qidong Liver Cancer Institute in 1996. The absence of HCC in the controls was verified by assessing AFP levels and ultrasonography when the blood samples were collected in 2006. All samples were HCV seronegative. According to the tenets of the Declaration of Helsinki (26), the study was approved by the ethics committees of Qidong County Liver Cancer Institute, (Qidong, China) and Fudan University (Shanghai, China). All participants provided written informed consent, including consent for genetic studies. Data do not contain any information that may lead to the identification of the patients.

Genotyping. DNA was extracted from peripheral blood mononuclear cells using SHENamp Blood DNA Kit according to the manufacturer's instructions (Shengyou Biotechnology Co., Ltd., Hangzhou, China). In phase 1, a total of 500,447 single-nucleotide polymorphisms (SNPs) were genotyped using an Affymetrix GeneChip Mapping 500k Array Set (Affymetrix, Santa Clara, CA, USA) in 50 cases and 50 controls. In phase 2, a total of 1,152 SNPs, selected from phase 1 , were genotyped in 282 cases and 278 controls using an Illumina GoldenGate genotyping assay (Illumina, San Diego, CA, USA) at Shanghai Biochip Co., Ltd. (Shanghai, China). The quality control, genotyping and data analyses were performed according to the protocols of the respective manufacturers. For phases 1 and 2, a DNA sample was deemed to have failed if it generated genotypes at $<93 \%$ of loci. A SNP was deemed to have failed if $<90 \%$ of DNA samples generated a genotype at the locus. In phase 2, 8 duplicate samples were genotyped to ensure quality of genotyping. For all 1,152 SNPs, $>99.8 \%$ concordant results were obtained. The genotyping results of 11 SNPs were also validated in 41 samples using the iPLEX Gold assay on the MassARRAY ${ }^{\circledR}$ platform (Sequenom, Inc., San Diego, CA, USA) and $>98.4 \%$ concordant results were obtained.

Statistical analysis. The statistical analysis of the GeneChip data was performed using Genotyping Console Software, version 4.0 (Affymetrix, Santa Clara, CA, USA) and BeadStudio Genotyping Module, version 3.2 (Illumina, San Diego, CA, USA). Combined analysis was conducted using Stata software version 10.0 (StataCorp, College Station, TX, USA). For each SNP, allele P-value, Cochran-Armitage trend P-value, odds ratio (ORs) and $95 \%$ confidence interval (CI) were calculated. The prior probability of HCC in control subjects was assigned at 0.01 , and false-positive report probability (FPRP) was used to assess the reliability of the associations (27). FPRP $<0.20$ was set as the significance threshold for the associations.

\section{Results}

Two stage GWA study identified 9 susceptibility loci. In phase 1 , the age distribution of 50 cases [mean age $( \pm$ SD) at diagnosis, 52.3 \pm 7.9 years] and 50 controls (mean age at diagnosis, $54.88 \pm 8.68$ years) was matched. Of the 50 cases, 11 had one or more first-degree relatives affected by HCC (mean age at diagnosis, 54.1 18.1 years). All 100 samples had a call rate of $>96 \%$. The call rate is the percentage of successful genotype calls per passing SNP. Exclusion criteria for SNPs included the following: i) overall frequency of SNP $<90 \%$; ii) minor allele frequency (MAF) $<0.05$; and iii) P-value of Hardy-Weinberg equilibrium (HWE) <0.001. Altogether, 279,757 eligible SNPs passed quality control and were included in further analyses. For each SNP, allele P-values, genotype $\mathrm{P}$-values and Cochran-Armitage trend $\mathrm{P}$-values were calculated. The minimum $\mathrm{P}$-value was designated as minP. For autosome, $\min \mathrm{P}=\min$ (allele_P, genotype_P , $\mathrm{P} \_$trend); for sex chromosome, $\min \mathrm{P}=\min$ (allele_P, allele_exact_P). There were 355 SNPs on autosomes and 2 SNPs on the X chromosome with $\min \mathrm{P}<1 \times 10^{-3}$. A total of 26 SNPs were identified with $\min \mathrm{P}<1 \times 10^{-4}$ (Table I). One SNP (rs2212522) demonstrated a significant association with $\mathrm{HCC}\left(\mathrm{P}_{\text {allele }}=5.23 \times 10^{-8}\right.$; $\mathrm{OR}_{\text {allele }}=4.96 ; 95 \%$ CI, 2.72-9.03). 
Table I. Twenty-six SNPs with $\operatorname{minP}<1 \times 10^{-4}$ in phase 1 .

\begin{tabular}{|c|c|c|c|c|c|c|c|}
\hline \multirow[b]{2}{*}{ dbSNP rsID ${ }^{a}$} & \multirow[b]{2}{*}{ Associated gene(s) } & \multicolumn{2}{|c|}{ Cases, $\mathrm{n}$} & \multicolumn{2}{|c|}{ Controls, $\mathrm{n}$} & \multirow[b]{2}{*}{ minP-value } & \multirow[b]{2}{*}{$\mathrm{OR}_{\text {allele }}$} \\
\hline & & A & $\mathrm{B}$ & A & $\mathrm{B}$ & & \\
\hline rs2212522 & L3MBTL4 & 68 & 32 & 30 & 70 & $7.65 \times 10^{-8}$ & 0.2016807 \\
\hline rs4713039 & NO145 & 44 & 56 & 77 & 23 & $1.81 \times 10^{-6}$ & 4.2608696 \\
\hline rs4539982 & $T B L 1 X R 1$ & 79 & 15 & 49 & 45 & $2.68 \times 10^{-6}$ & 0.2067511 \\
\hline rs9877175 & $T B L 1 X R 1$ & 18 & 80 & 49 & 51 & $5.25 \times 10^{-6}$ & 4.2701525 \\
\hline rs4277177 & TMEM16F & 51 & 45 & 62 & 36 & $8.52 \times 10^{-6}$ & 1.5196078 \\
\hline rs8031646 & $A R R D C 4$ & 72 & 26 & 42 & 56 & $1.40 \times 10^{-5}$ & 0.2708333 \\
\hline rs11057529 & FAM101A & 17 & 83 & 45 & 55 & $1.40 \times 10^{-5}$ & 3.9946524 \\
\hline rs7069096 & LYZL1 & 36 & 62 & 67 & 33 & $2.03 \times 10^{-5}$ & 3.4966332 \\
\hline rs946351 & NO145 & 51 & 49 & 22 & 78 & $2.05 \times 10^{-5}$ & 0.2709904 \\
\hline rs12044483 & FLJ32784, UBXD3 & 39 & 61 & 69 & 31 & $2.08 \times 10^{-5}$ & 3.4813896 \\
\hline rs10926832 & PLD5 & 32 & 66 & 61 & 39 & $2.16 \times 10^{-5}$ & 3.2259615 \\
\hline rs1334125 & PRMT6 & 34 & 66 & 64 & 36 & $2.19 \times 10^{-5}$ & 3.4509804 \\
\hline rs12580388 & TMEM132D & 80 & 20 & 53 & 47 & $3.17 \times 10^{-5}$ & 0.2819149 \\
\hline rs6910232 & NO145 & 64 & 34 & 35 & 63 & $3.43 \times 10^{-5}$ & 0.2951389 \\
\hline rs7854810 & ENST00000380100 & 97 & 3 & 76 & 22 & $3.80 \times 10^{-5}$ & 0.1068416 \\
\hline rs12034802 & PRMT6 & 60 & 30 & 37 & 63 & $4.42 \times 10^{-5}$ & 0.2936508 \\
\hline rs7870157 & ENST00000387810 & 4 & 96 & 24 & 76 & $4.59 \times 10^{-5}$ & 7.5789474 \\
\hline rs1883165 & $F L J 32784$ & 65 & 31 & 35 & 57 & $4.60 \times 10^{-5}$ & 0.2928475 \\
\hline rs2292723 & TMEM132D & 11 & 89 & 32 & 66 & $5.63 \times 10^{-5}$ & 3.9228651 \\
\hline rs 10735541 & TLE4 & 32 & 68 & 13 & 87 & $5.93 \times 10^{-5}$ & 0.3175287 \\
\hline rs1543940 & LOC440337, FAM86A & 13 & 79 & 36 & 54 & $7.63 \times 10^{-5}$ & 4.0512821 \\
\hline rs9571852 & $N B E A$ & 14 & 86 & 38 & 62 & $7.89 \times 10^{-5}$ & 3.7649773 \\
\hline rs9949516 & L3MBTL4 & 31 & 63 & 60 & 38 & $8.92 \times 10^{-5}$ & 3.2088285 \\
\hline rs6828409 & $E R E G, E P G N$ & 75 & 25 & 47 & 51 & $9.16 \times 10^{-5}$ & 0.3071895 \\
\hline rs7105477 & $A P 2 A 2$ & 82 & 8 & 68 & 32 & $9.56 \times 10^{-5}$ & 0.2073171 \\
\hline rs4417097 & PRMT6, AMYIC & 39 & 53 & 69 & 29 & $9.76 \times 10^{-5}$ & 3.2334218 \\
\hline
\end{tabular}

${ }^{a}$ Accessible at http://www.ncbi.nlm.nih.gov/SNP/. SNP, single-nucleotide polymorphism. A represents the total number of major allele in cases or controls (n); B represents the total number of minor allele in cases or controls (n).

In phase 2, $282 \mathrm{HCC}$ cases and 278 controls were recruited from Qidong. Of the HCC cases, 61 (21\%) had a family history of HCC in a first or second-degree relative. The age distributions were $51.4 \pm 10.0$ and $53.7 \pm 10.6$ years in cases and controls, respectively. The selected 1,152 SNPs included 4 categories: i) SNPs whose minP in phase 1 was $<1 \times 10^{-3}$ or SNPs well clustered in chromosome with $\min \mathrm{P}<0.05(\mathrm{n}=398)$; ii) predicted deleterious non-synonymous SNPs (nsSNPs) $(n=430)$ of the nearest genes; iii) SNPs possibly associated with copy number variation $(\mathrm{CNV})(\mathrm{n}=315)$; and iv) SNPs located at 8q24 which had been reported to be associated with other types of cancers $(n=9$ : rs13254738, rs6983561, rs16901979, rs13281615, rs10505447, rs10808556, rs6983267, rs7000448 and rs1447295) (28-33).

All 560 samples had a call rate of $>93 \%$. Of the selected 1,152 SNPs, 598 passed the quality control following the exclusion procedure (MAF $<0.05$, HWE disequilibrium $\mathrm{P}<0.001$ and call frequency $<0.95$ ). There were 35 SNPs with unadjusted $\mathrm{P}_{\text {allele }}<0.05$. Of these, $8 \mathrm{SNPs}$ whose minor allele number was $\leq 3$ were further excluded, leaving 27 SNPs with unadjusted $\mathrm{P}_{\text {allele }}<0.05$. The most significant signal in phase 1 , rs2212522, was replicated in phase 2 with $\mathrm{P}_{\text {allele }}<0.05$ and combined $\mathrm{P}_{\text {allele }}=7.91 \times 10^{-5}$. Out of 27 SNPs, 20 were genotyped in phases 1 and 2, and 7 SNPs were genotyped only in phase 2. Combined analysis of the 20 SNPs revealed that there were 15 SNPs with combined $P_{\text {allele }}<0.05$. Thus, there were 22 SNPs with combined allele P-value or with phase 2 allele P-value of $<0.05$ (Table II). As all controls were men with HBsAg seropositivity, a prior probability of 0.01 for HCC occurrence was assigned and FPRP was calculated (34). The results revealed that 9 of the 22 SNPs were associated with HCC (FPRP $<0.20)$ (Table III). CNV was validated by genotyping 315 high density SNPs using the Illumina GoldenGate platform and quantitative polymerase chain reaction (qPCR) analysis; this identified a number of CNVs in $\mathrm{HCC}$, reported in other studies $(35,36)$. No associations were identified between the 9 SNPs in 8q24 and HCC.

Genes associated with the 9 susceptibility loci. $\mathrm{rs} 2120243$ $(\mathrm{C}>\mathrm{A})$ maps within the fourth intron of ventricular zone expressed PH domain homolog 1 [VEPHI; HUGO Gene Nomenclature Committee (HGNC) ID: 25735]. VEPH1 maps at 3q24-25 and covers $273.88 \mathrm{~kb}$. 
Table II. Twenty-two SNPs with allele $\mathrm{P}<0.05$ in phase 2 or combined allele $\mathrm{P}<0.05$.

\begin{tabular}{|c|c|c|c|c|c|c|}
\hline \multirow[b]{2}{*}{ dbSNP rsID ${ }^{a}$} & \multirow{2}{*}{$\begin{array}{l}\text { Associated } \\
\text { gene }\end{array}$} & \multirow[b]{2}{*}{ Chromosome } & \multirow[b]{2}{*}{ Position } & \multicolumn{3}{|c|}{ Allele P-value } \\
\hline & & & & Phase 1 & Phase 2 & Combined \\
\hline rs2120243 & VEPH1 & $3 q 24-25$ & 158630262 & $1.37 \times 10^{-4}$ & $3.23 \times 10^{-4}$ & $2.00 \times 10^{-6}$ \\
\hline rs1350171 & FZD4 & $11 \mathrm{q} 14.2$ & 86322037 & $1.68 \times 10^{-4}$ & $9.16 \times 10^{-4}$ & $7.47 \times 10^{-6}$ \\
\hline rs1048338 & FZD4 & $11 \mathrm{q} 14.2$ & 86310465 & $1.57 \times 10^{-4}$ & $1.44 \times 10^{-3}$ & $1.11 \times 10^{-5}$ \\
\hline rs2212522 & L3MBTL4 & $18 \mathrm{p} 11.31$ & 5890773 & $5.23 \times 10^{-8}$ & $4.81 \times 10^{-2}$ & $7.91 \times 10^{-5}$ \\
\hline rs7116140 & FZD4 & $11 \mathrm{q} 14.2$ & 86313003 & $2.14 \times 10^{-4}$ & $1.20 \times 10^{-2}$ & $1.76 \times 10^{-4}$ \\
\hline rs4480667 & РCDH9 & $13 q 14.3$ & 66825714 & $6.60 \times 10^{-1}$ & $1.92 \times 10^{-4}$ & $3.02 \times 10^{-4}$ \\
\hline rs4417097 & PRMT6 & $1 \mathrm{p} 13.3$ & 106601576 & $8.78 \times 10^{-5}$ & $2.79 \times 10^{-2}$ & $4.27 \times 10^{-4}$ \\
\hline rs9893681 & $L H X 1$ & $17 q 12$ & 32362128 & $4.47 \times 10^{-4}$ & $2.82 \times 10^{-2}$ & $9.31 \times 10^{-4}$ \\
\hline rs4767254 & $T B X 3$ & $12 \mathrm{q} 24.1$ & 113682775 & $6.13 \times 10^{-4}$ & $3.22 \times 10^{-2}$ & $1.18 \times 10^{-3}$ \\
\hline rs132024 & $P H F 21 B$ & $22 q 13.31$ & 43804508 & $5.77 \times 10^{-4}$ & $4.65 \times 10^{-2}$ & $2.20 \times 10^{-3}$ \\
\hline rs4561519 & $K I F 2 B$ & $17 q 22$ & 49256702 & $1.90 \times 10^{-1}$ & $9.26 \times 10^{-3}$ & $3.61 \times 10^{-3}$ \\
\hline rs729565 & CNTNAP2 & $7 q 35$ & 146668586 & $3.70 \times 10^{-1}$ & $1.02 \times 10^{-2}$ & $6.49 \times 10^{-3}$ \\
\hline rs4726849 & CNTNAP2 & $7 q 35$ & 146704681 & $3.40 \times 10^{-1}$ & $3.23 \times 10^{-2}$ & $1.90 \times 10^{-2}$ \\
\hline rs10500181 & CNTNAP2 & $7 q 35$ & 146704487 & $3.60 \times 10^{-1}$ & $3.75 \times 10^{-2}$ & $2.30 \times 10^{-2}$ \\
\hline rs12532315 & CNTNAP2 & $7 q 35$ & 146730215 & $5.40 \times 10^{-1}$ & $4.95 \times 10^{-2}$ & $4.04 \times 10^{-2}$ \\
\hline rs3818605 & PTPRA & 20p12 & 2788773 & & $6.12 \times 10^{-3}$ & \\
\hline rs9898643 & $K I F 2 B$ & $17 q 22$ & 49254648 & & $7.49 \times 10^{-3}$ & \\
\hline rs3806523 & SH3BP4 & $2 q 37.1$ & 235523908 & & $1.33 \times 10^{-2}$ & \\
\hline rs1155569 & RPL38 & $17 q 23$ & 61082421 & & $2.54 \times 10^{-2}$ & \\
\hline rs1057090 & MCPHI & $8 p 23.1$ & 6466450 & & $2.80 \times 10^{-2}$ & \\
\hline rs17138848 & COMMD10 & $5 q 23.1$ & 115447202 & & $4.22 \times 10^{-2}$ & \\
\hline rs730819 & PTPRA & 20p12 & 2793130 & & $4.28 \times 10^{-2}$ & \\
\hline
\end{tabular}

${ }^{a}$ Accessible at http://www.ncbi.nlm.nih.gov/SNP/. SNP, single-nucleotide polymorphism.

Table III. Nine SNPs with combined allele $\mathrm{P}<0.05$ and FPRP $<0.20$.

\begin{tabular}{|c|c|c|c|c|c|c|c|}
\hline \multirow[b]{2}{*}{ dbSNP rsID ${ }^{a}$} & \multirow{2}{*}{$\begin{array}{l}\text { Associated } \\
\text { gene }\end{array}$} & \multicolumn{3}{|c|}{ Allele P-value } & \multirow[b]{2}{*}{$\mathrm{OR}_{\text {allele }}$} & \multirow[b]{2}{*}{$95 \% \mathrm{CI}$} & \multirow[b]{2}{*}{ FPRP } \\
\hline & & Phase 1 & Phase 2 & Combined & & & \\
\hline rs2120243 & VEPHI & $1.37 \times 10^{-4}$ & $3.32 \times 10^{-4}$ & $2.00 \times 10^{-6}$ & 1.76 & $1.39-2.22$ & $<0.001$ \\
\hline rs1350171 & FZD4 & $1.68 \times 10^{-4}$ & $9.28 \times 10^{-4}$ & $6.48 \times 10^{-6}$ & 1.66 & $1.33-2.07$ & 0.014 \\
\hline rs1048338 & FZD4 & $1.58 \times 10^{-4}$ & $1.44 \times 10^{-3}$ & $1.11 \times 10^{-5}$ & 1.64 & $1.31-2.04$ & 0.046 \\
\hline rs2212522 & L3MBTLA & $5.23 \times 10^{-8}$ & $4.81 \times 10^{-2}$ & $7.91 \times 10^{-5}$ & 1.57 & $1.25-1.97$ & 0.019 \\
\hline rs7116140 & FZD4 & $2.14 \times 10^{-4}$ & $1.20 \times 10^{-2}$ & $1.76 \times 10^{-4}$ & 1.51 & $1.22-1.88$ & 0.039 \\
\hline rs4480667 & РCDH9 & $6.60 \times 10^{-1}$ & $1.92 \times 10^{-4}$ & $3.02 \times 10^{-4}$ & 1.52 & $1.21-1.90$ & 0.037 \\
\hline rs4417097 & PRMT6 & $8.78 \times 10^{-5}$ & $2.78 \times 10^{-2}$ & $4.27 \times 10^{-4}$ & 1.48 & $1.19-1.85$ & 0.057 \\
\hline rs9893681 & $L H X 1$ & $4.46 \times 10^{-4}$ & $2.82 \times 10^{-2}$ & $9.31 \times 10^{-4}$ & 1.65 & $1.22-2.21$ & 0.159 \\
\hline rs4561519 & $K I F 2 B$ & $1.90 \times 10^{-1}$ & $9.26 \times 10^{-3}$ & $3.61 \times 10^{-3}$ & 1.52 & $1.14-2.02$ & 0.176 \\
\hline
\end{tabular}

${ }^{a}$ Accessible at http://www.ncbi.nlm.nih.gov/SNP/. SNP, single-nucleotide polymorphism; FPRP, false-positive report probability; CI, confidence interval.

Frizzled homolog 4 (FZD4; HGNC ID: 4042) is a member of the frizzled gene family, maps at 11q14.2 and covers $9.73 \mathrm{~kb}$. The majority of frizzled receptors are coupled to the $\beta$-catenin signaling pathway. It has been reported FZD4 is associated with numerous types of cancer (37). In the present study, 3 SNPs (rs1048338, rs7116140 and rs1350171) were identified in the downstream 12-23 kb of FZD4. Haploview version 4.11 (The Broad Institute) revealed that the 3 SNPs are in one strong linkage disequilibrium (LD) block (Fig. 1). Using the haplotype analysis software PLINK (pngu.mgh.harvard.edu/purcell/plink/), it was demonstrated that the haplotype exhibited significantly different distributions between cases and controls $(\mathrm{P}<0.01)$. 


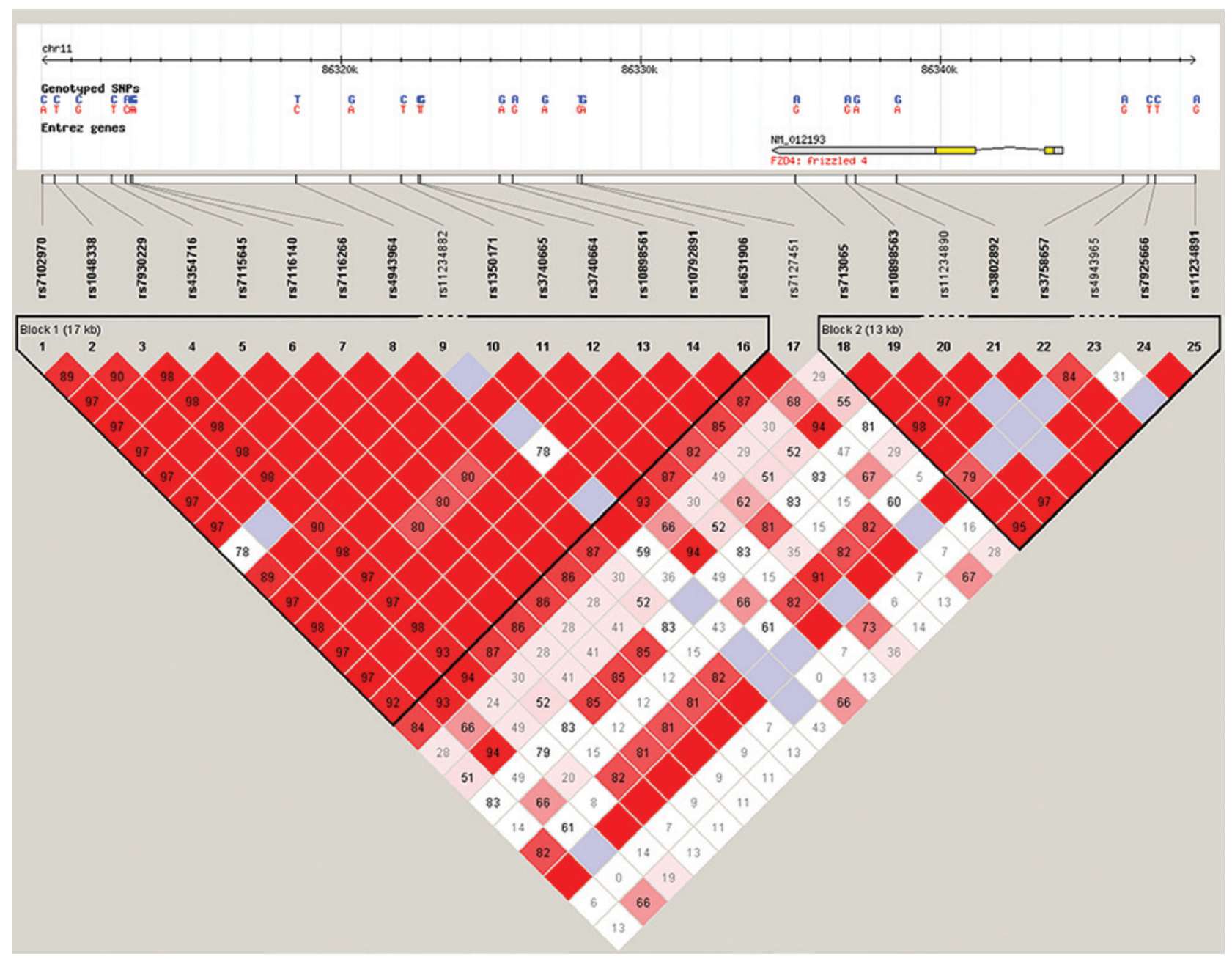

Figure 1. Haploview revealed the linkage disequilibrium block contained rs1048338, rs7116140 and rs1350171. The block covers $12 \mathrm{~kb}$ containing 19 SNPs. SNPs, single-nucleotide polymorphisms.

rs4480667 is located in the $125 \mathrm{~kb}$ upstream of protocadherin 9 (PCDH9; HGNC ID: 8661) and maps in a $24 \mathrm{~kb}$ block (38). $P C D H 9$, which belongs to the protocadherin gene family, maps at $13 \mathrm{q} 14.3-\mathrm{q} 21.1$ and covers $927.62 \mathrm{~kb}$. It has been reported that $\mathrm{CNV}$ of $\mathrm{PCDH} 9$ may be associated with glioblastoma as a tumor suppressor gene (TSG) (39). Patch 1.0 revealed that allele A of $\operatorname{rs} 4480667(A>G)$ created a new binding site for the transcription factors C-Ets-1 (HGNC ID: 3488) and Elf-1 (HGNC ID: 3316). These two transcription factors have been reported to be associated with several cancer types, including lung cancer and HCC (40).

rs9893681 maps at the upstream $6.4 \mathrm{~kb}$ of the LIM homeobox 1 (LHXI) gene. LHXI (HGNC ID: 6593) maps at $17 \mathrm{q} 12$ and covers $7.15 \mathrm{~kb}$. It has been reported the CNV of $L H X 1$ is associated with gastric cancer (41). Patch 1.0 indicated that allele A of rs9893681 (T>A) created a new binding site for transcription factor Fushi tarazu (FTZ gene). Liu et al (42) reported that FTZ regulated the ubiquitin E3 ligase complex factor Speckle-type POZ protein (SPOP; HGNC ID: 11254), which mediated degradation of the Jun-kinase phosphatase, thereby inducing tumor necrosis factor/Eiger-dependent apoptosis (42). The human homolog of $F T Z$, nuclear receptor subfamily 5 group A member 2 (NR5A2; HGNC ID: 7984) has been shown to play critical roles in various cancer types $(43,44)$. rs4417097 is located in a region of gene desert, the nearest gene being protein arginine methyltransferase 6 (PRMT6; HGNC ID: 18241). rs4417097 maps in the upstream $799 \mathrm{~kb}$ of PRMT6. A previous GWAS reported that PRMT6 gene is involved in acquired immune deficiency syndrome (45). Another study reported that thrombospondin-1 was a transcriptional repression target of PRMT6, and suggested that neutralizing the activity of PRMT6 could inhibit tumor progression (46).

rs 4561519 is a nsSNP of kinesin family member $2 \mathrm{~B}$ (KIF $2 B$; HGNC ID: 29443). KIF2B has been proposed to participate in the process of microtubule-based movement. Three protein function prediction software packages: SIFT (sift.jcvi.org/), Polyphen (genetics.bwh.harvard.edu/pph2/) and SNPs3D (snps3d.org/), predicted that rs4561519 is deleterious to the protein's function $(47,48)$.

L(3)mbt-like 4 (L3MBTL4) maps on chromosome 18, at 18p11.3. It covers $460.53 \mathrm{~kb}$, from 6405235 to 5944705 [National Center for Biotechnology Information (NCBI) 36, March 2006; ncbi.nlm.nih.gov/IEB/Research/Acembly/av.cgi?c=ge neid\&org $=9606 \& l=91133]$, on the reverse strand. $r$ 2212522 maps to $53.9 \mathrm{~kb}$ downstream of L3MBTL4. Functionally, this gene has been proposed to participate in various processes, including cell adhesion, platelet activation and regulation of 


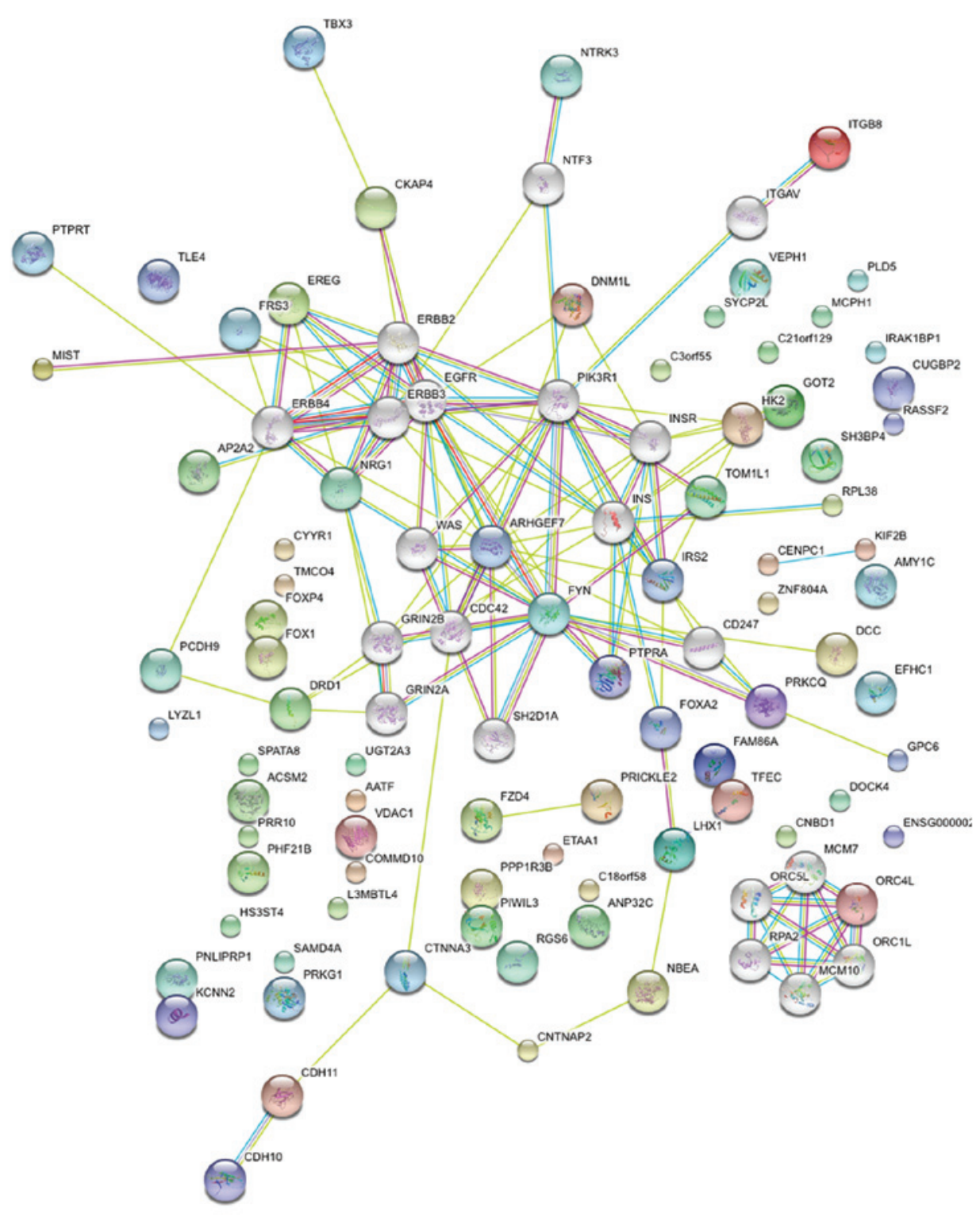

Figure 2. Protein network configuration by STRING.

transcription. The protein is also predicted to have molecular functions (transcription factor activity and zinc ion binding) and to localize to various compartments (integrin complex, cytoplasm, extracellular space and the nucleus). L3MBT has been reported to be a TSG in Drosophila (49). In addition, one study reported that $L 3 M B T L 4$ was associated with HCC (50).

Gene gene interactions. In order to find the gene-gene interactions, we selected all SNPs with combined $\mathrm{P}_{\text {allele }}<0.05$ and SNPs with $\mathrm{P}_{\text {allele }}<0.05$ in phase 2 and searched for the nearest genes using the NCBI Map Viewer (www.ncbi.nlm.nih.gov/mapview/). A total of 109 SNPs associated with 84 genes were identified. Protein-protein interaction networks were then explored using STRING software (string-db.org/); 80 proteins were recognized and analyzed. By adding 20 protein notes automatically with STRING, many crucial proteins were identified, including EGFR, ERBBs, FYN, CDC42, PIK3R1, ARHGEF, INS, INSR, CDC42 and PRKCQ (Fig. 2). These genes involved a number of important signaling pathways involved in carcinogenesis, such as transforming growth factor $\beta$, insulin/phosphoinositide 3 kinase $(\mathrm{PI} 3 \mathrm{~K})$ and $\mathrm{Wnt} / \beta$-catenin.

\section{Discussion}

The success of GWAS relies on much of the risk of common diseases being due to common genetic variants; however, evidence for this hypothesis is inconclusive, and the possibility that some complex diseases are due to certain rare variants with high genetic risk cannot be excluded. Therefore, the present study investigated both common variants and relatively rare variants of the selected nsSNPs, with possibly deleterious effects on protein function, to perform a two-stage GWAS.

Chen et al (33) genotyped over 350,000 genome-wide autosomal SNPs by using Illumina Human 610-Quad BeadChips in over 6,000 Han Chinese samples from ten provinces, showing that, in the Han Chinese population, geographic matching is a good proxy for genetic matching (51). In phase 1 of the present study, 100 participants were enrolled from Qidong, China. 
Therefore, we considered it unnecessary to conduct a population stratification analysis. In order to increase the statistical power to search for genetic risk factors, potential confounding factors (gender, ethnicity, HBV status and age) were controlled by selecting only male HCC patients (including familial HCC patients) and male controls with HBsAg seropositivity from Qidong, where there is a high incidence of HCC. Due to the relatively small sample size (660 samples) of this GWAS, the associations did not reach previously established statistical criteria for GWAS $\left(\mathrm{P}<5 \times 10^{-7}\right)(52)$. In addition, certain researchers consider the Bonferroni adjustment too strict and not applicable to small studies (53). In the current study, by using the FPRP criterion (FPRP<0.20), 9 SNPs were identified to be associated with HCC. The majority of these SNPs were located in a gene region, including intron, promoter and coding regions. The strongest statistical evidence for an association was found in rs2120243, which maps within the fourth intron of VEPH1. According to Haploview, rs2120243 is in a $25 \mathrm{~kb}$ block including 19 SNPs. Teleman et al (54) identified the Drosophila melted protein as a modulator of the insulin/PI3K signaling pathway; VEPH1 in Homo sapiens and Drosophila melted protein are homologous proteins. One study has reported $V E P H I$ to be a cancer-associated gene in breast cancer (55). By using the online functional protein network software STRING, VEPHI was found to be connected to ACVR1, TGFBR1, AKT1, SRC, FRAPl and TP53 (56). Patch 1.0 software, which predicts changes in the binding sites of transcription factors, revealed that allele A of rs 2120243 creates a new binding site for transcription factor retinoid $\mathrm{X}$ receptor $\alpha$ (RXR- $\alpha)$ (57). It has been reported that RXR- $\alpha$ is associated with HCC (58). In addition, a recent GWAS conducted in China reported a susceptibility locus KIFIB on 1p36.22 (rs17401966) for HBV-related HCC (18). The current GWAS discovery analysis did not reveal a consistent result for the association between rs17401966 and the development of HBV-related HCC. However, one nsSNP (rs4561519) of the $K I F 2 B$ gene was associated with HCC in this study. Three protein function prediction softwares (SIFT, Polyphen and SNPs3D) all predicted that rs 4561519 was deleterious to the protein's function. KIFIB and KIF $2 B$ belong to the kinesin family, which may indicate that kinesin families are associated with $\mathrm{HCC}$. We further investigated the protein expression of $K I F 2 B$ in chronic HBV carriers by immunohistochemistry and western blot analysis in another unpublished study. Significantly increased expression of $K I F 2 B$ was detected in adjacent non-tumor liver tissues compared with that of paired HCC tissues (data not shown). The exact functional consequences of rs17401966 remain unknown. Further studies will be needed to finely map and identify the causative polymorphism and to clarify which genes drive the genetic association. Using STRING network analysis, many cancer-related genes were identified, and these were involved in various important signaling pathways associated with HCC that have been validated by other studies $(59,60)$.

Previous studies have clearly demonstrated the existence of a subpopulation structure among the Chinese Han population along the north-south axis. In the present study, all cases and controls were residents of Qidong. Therefore, the findings should be free of adverse effects of population stratification. The sample size in this pilot two-stage GWAS was relatively small and had relatively limited statistical power to detect risk alleles with relatively low allele frequency $(\mathrm{MAF}<0.1)$ or genetic power $(\mathrm{OR}<1.2)$. Due to these limitations, the results must be interpreted and conclusions made with caution. At present, we are collecting more samples and intend to investigate certain proposed SNPs and genotypes in larger studies to replicate and validate the associations. The risk alleles and related gene functions must also be studied further.

In conclusion, by conducting two-stage GWAS and mining bioinformatic data, the present study has identified a number of potential susceptibility loci for HCC in male Chinese individuals with HBsAg seropositivity. These findings offer valuable clues in the study of hepatocarcinogenesis and may have potential clinical value. The associations and molecular mechanisms of HCC merit further research.

\section{Acknowledgements}

The authors would like to thank the clinical investigators involved in the present study. This study was supported by the China Ministry of Health (no. W201202), National Natural Science Foundation (no. 81302056), Natural Science Foundation of Jiangsu Province (no. BK2012225) and Foundation of Jiangsu Province (no. WS056).

\section{References}

1. Farazi PA and DePinho RA: Hepatocellular carcinoma pathogenesis: From genes to environment. Nat Rev Cancer 6: 674-687, 2006

2. Shariff MI, Cox IJ, Gomaa AI, Khan SA, Gedroyc W and Taylor-Robinson SD: Hepatocellular carcinoma: Current trends in worldwide epidemiology, risk factors, diagnosis and therapeutics. Expert Rev Gastroenterol Hepatol 3: 353-367, 2009.

3. El-Serag HB and Rudolph KL: Hepatocellular carcinoma: Epidemiology and molecular carcinogenesis. Gastroenterology 132: 2557-2576, 2007.

4. Trinchet JC, Alperovitch A, Bedossa P, Degos F, Hainaut P and Beers BV: Epidemiology, prevention, screening and diagnosis of hepatocellular carcinoma. Bull Cancer 96: 35-43, 2009 (In French).

5. Poon D, Anderson BO, Chen LT, Tanaka K, Lau WY, Van Cutsem E, Singh H, Chow WC, Ooi LL, Chow P, et al; Asian Oncology Summit: Management of hepatocellular carcinoma in Asia: Consensus statement from the Asian Oncology Summit 2009. Lancet Oncol 10: 1111-1118, 2009.

6. Yeh FS, Yu MC, Mo CC, Luo S, Tong MJ and Henderson BE: Hepatitis B virus, aflatoxins, and hepatocellular carcinoma in southern Guangxi, China. Cancer Res 49: 2506-2509, 1989.

7. Long XD, Ma Y, Wei YP and Deng ZL: The polymorphisms of GSTM1, GSTT1, HYL1*2, and XRCC1, and aflatoxin B1-related hepatocellular carcinoma in Guangxi population, China. Hepatol Res 36: 48-55, 2006.

8. Imaizumi T, Higaki Y, Hara M, Sakamoto T, Horita M, Mizuta T, Eguchi Y, Yasutake T, Ozaki I, Yamamoto K, et al: Interaction between cytochrome P450 1A2 genetic polymorphism and cigarette smoking on the risk of hepatocellular carcinoma in a Japanese population. Carcinogenesis 30: 1729-1734, 2009.

9. Nahon P, Sutton A, Rufat P,Ziol M, Thabut G, Schischmanoff PO, Vidaud D, Charnaux N, Couvert P, Ganne-Carrie N, et al: Liver iron, HFE gene mutations, and hepatocellular carcinoma occurrence in patients with cirrhosis. Gastroenterology 134: 102-110, 2008.

10. Migita K, Miyazoe S, Maeda Y, Daikoku M, Abiru S, Ueki T, Yano K, Nagaoka S, Matsumoto T, Nakao K, et al: Cytokine gene polymorphisms in Japanese patients with hepatitis B virus infection - association between TGF-beta1 polymorphisms and hepatocellular carcinoma. J Hepatol 42: 505-510, 2005.

11. Ognjanovic S, Yuan JM, Chaptman AK, Fan Y and Yu MC: Genetic polymorphisms in the cytokine genes and risk of hepatocellular carcinoma in low-risk non-Asians of USA. Carcinogenesis 30: 758-762, 2009. 
12. Hirschhorn JN and Daly MJ: Genome-wide association studies for common diseases and complex traits. Nat Rev Genet 6: 95-108, 2005.

13. De Bakker PI, Yelensky R, Pe'er I, Gabriel SB, Daly MJ and Altshuler D: Efficiency and power in genetic association studies. Nat Genet 37: 1217-1223, 2005.

14. Florez JC, Manning AK, Dupuis J, McAteer J, Irenze K, Gianniny L, Mirel DB, Fox CS, Cupples LA and Meigs JB: A $100 \mathrm{~K}$ genome-wide association scan for diabetes and related traits in the Framingham Heart Study: Replication and integration with other genome-wide datasets. Diabetes 56: 3063-3074, 2007.

15. Rothman N, Garcia-Closas M, Chatterjee N, Malats N, Wu X, Figueroa JD, Real FX, Van Den Berg D, Matullo G, Baris D, et al: A multi-stage genome-wide association study of bladder cancer identifies multiple susceptibility loci. Nat Genet 42(11):978-84, 2010

16. Wu C, Miao X, Huang L, Che X, Jiang G, Yu D, Yang X, Cao G, Hu Z, Zhou Y, et al: Genome-wide association study identifies five loci associated with susceptibility to pancreatic cancer in Chinese populations. Nat Genet 44: 62-66, 2011.

17. Han JW, Zheng HF, Cui Y, Sun LD, Ye DQ, Hu Z, Xu JH, Cai ZM, Huang W, Zhao GP, et al: Genome-wide association study in a Chinese Han population identifies nine new susceptibility loci for systemic lupus erythematosus. Nat Genet 41: 1234-1237, 2009.

18. Kurbanov F, Tanaka Y and Mizokami M: Geographical and genetic diversity of the human hepatitis B virus. Hepatol Res 40: 14-30, 2010.

19. Chen CJ and Chen DS: Interaction of hepatitis B virus, chemical carcinogen, and genetic susceptibility: Multistage hepatocarcinogenesis with multifactorial etiology. Hepatology 36: 1046-1049, 2002.

20. Ming L, Thorgeirsson SS, Gail MH, Lu P, Harris CC, Wang N, Shao Y, Wu Z, Liu G, Wang X, et al: Dominant role of hepatitis B virus and cofactor role of aflatoxin in hepatocarcinogenesis in Qidong, China. Hepatology 36: 1214-1220, 2002

21. Zhang H, Zhai Y, Hu Z, Wu C, Qian J, Jia W, Ma F, Huang W, Yu L, Yue W, et al: Genome-wide association study identifies 1p36.22 as a new susceptibility locus for hepatocellular carcinoma in chronic hepatitis B virus carriers. Nat Genet 42: 755-758, 2010.

22. Qu LS, Liu TT, Jin F, Guo YM, Chen TY, Ni ZP and Shen XZ: Combined pre-S deletion and core promoter mutations related to hepatocellular carcinoma: A nested case-control study in China. Hepatol Res 41: 54-63, 2011.

23. Qu L, Kuai X, Liu T, Chen T, Ni Z and Shen X: Pre-S deletion and complex mutations of hepatitis $\mathrm{B}$ virus related to young age hepatocellular carcinoma in Qidong, China. PLoS One 8: e59583, 2013

24. Qu LS, Liu JX, Liu TT, Shen XZ, Chen TY, Ni ZP and Lu CH: Association of hepatitis B virus pre-S deletions with the development of hepatocellular carcinoma in Qidong, China. PLoS One 9: e98257, 2014.

25. Llovet JM, Fuster J and Bruix J; Barcelona-Clínic Liver Cancer Group: The Barcelona approach: Diagnosis, staging, and treatment of hepatocellular carcinoma. Liver Transpl 10: S115-S120, 2004.

26. World Medical Association Declaration of Helsinki: Ethical principles for medical research involving human subjects. JAMA 284: 3043-3045, 2000

27. Al Olama AA, Kote-Jarai Z, Giles GG, Guy M, Morrison J, Severi G, Leongamornlert DA, Tymrakiewicz M, Jhavar S, Saunders E, et al: Multiple loci on 8q24 associated with prostate cancer susceptibility. Nat Genet 41: 1058-1060, 2009.

28. Kiemeney LA, Thorlacius S, Sulem P, Geller F, Aben KK, Stacey SN, Gudmundsson J, Jakobsdottir M, Bergthorsson JT, Sigurdsson A, et al: Sequence variant on 8q24 confers susceptibility to urinary bladder cancer. Nat Genet 40: 1307-1312, 2008

29. Fletcher O, Johnson N, Gibson L, Coupland B, Fraser A Leonard A, dos Santos Silva I, Ashworth A, Houlston R and Peto J: Association of genetic variants at $8 \mathrm{q} 24$ with breast cancer risk. Cancer Epidemiol Biomarkers Prev 17: 702-705, 2008.

30. Beebe-Dimmer JL, Levin AM, Ray AM, Zuhlke KA Machiela MJ, Halstead-Nussloch BA, Johnson GR, Cooney KA and Douglas JA: Chromosome 8q24 markers: Risk of early-onset and familial prostate cancer. Int J Cancer 122: 2876-2879, 2008.

31. Cheng I, Plummer SJ, Jorgenson E, Liu X, Rybicki BA, Casey G and Witte JS: 8q24 and prostate cancer: Association with advanced disease and meta-analysis. Eur J Hum Genet 16: 496-505, 2008

32. Yeager M, Orr N, Hayes RB, Jacobs KB, Kraft P, Wacholder S, Minichiello MJ, Fearnhead P, Yu K, Chatterjee N, et al: Genome-wide association study of prostate cancer identifies a second risk locus at 8q24. Nat Genet 39: 645-649, 2007.
33. Chen CF, Hsu EC, Lin KT, Tu PH, Chang HW, Lin CH, Chen YJ, $\mathrm{Gu}$ DL, Lin CH, Wu JY, et al: Overlapping high-resolution copy number alterations in cancer genomes identified putative cancer genes in hepatocellular carcinoma. Hepatology 52: 1690-1701, 2010.

34. Jia D, Wei L, Guo W, Zha R, Bao M, Chen Z, Zhao Y, Ge C, Zhao F, Chen T, et al: Genome-wide copy number analyses identified novel cancer genes in hepatocellular carcinoma. Hepatology 54: 1227-1236, 2011.

35. Wacholder S, Chanock S, Garcia-Closas M, El Ghormli L and Rothman N: Assessing the probability that a positive report is false: An approach for molecular epidemiology studies. J Nat Cancer Inst 96: 434-442, 2004.

36. Blakely TA, Bates MN, Baker MG and Tobias M: Hepatitis B carriage explains the excess rate of hepatocellular carcinoma for Maori, Pacific Island and Asian people compared to Europeans in New Zealand. Int J Epidemiol 28: 204-210, 1999.

37. Katoh M: Networking of WNT, FGF, Notch, BMP, and Hedgehog signaling pathways during carcinogenesis. Stem Cell Rev 3: 30-38, 2007.

38. Purcell S, Neale B, Todd-Brown K, Thomas L, Ferreira MA, Bender D, Maller J, Sklar P, de Bakker PI, Daly MJ, et al: PLINK: A tool set for whole-genome association and population-based linkage analyses. Am J Hum Genet 81: 559-575, 2007.

39. de Tayrac M, Etcheverry A, Aubry M, Saïkali S, Hamlat A, Quillien V, Le Treut A, Galibert MD and Mosser J: Integrative genome-wide analysis reveals a robust genomic glioblastoma signature associated with copy number driving changes in gene expression. Genes Chromosomes Cancer 48: 55-68, 2009.

40. Mamori S and Tajiri H: Ets-1 is increased in anticancer drug-containing media and hypoxic cultures, similar to TACE. Scand J Gastroenterol 44: 507-508, 2009.

41. Varis A, Wolf M, Monni O, Vakkari ML, Kokkola A, Moskaluk C, Frierson H Jr, Powell SM, Knuutila S, Kallioniemi A, et al: Targets of gene amplification and overexpression at $17 \mathrm{q}$ in gastric cancer. Cancer Res 62: 2625-2629, 2002.

42. Liu J, Ghanim M, Xue L, Brown CD, Iossifov I, Angeletti C, Hua S, Nègre N, Ludwig M, Stricker T, et al: Analysis of Drosophila segmentation network identifies a JNK pathway factor overexpressed in kidney cancer. Science 323: 1218-1222, 2009.

43. Xing Y, Shi S, Le L, Lee CA, Silver-Morse L and Li WX Evidence for transgenerational transmission of epigenetic tumor susceptibility in Drosophila. PLoS Genet 3: 1598-1606, 2007.

44. Hahn SA, Schutte M, Hoque AT, Moskaluk CA, da Costa LT, Rozenblum E, Weinstein CL, Fischer A, Yeo CJ, Hruban RH, et al: DPC4, a candidate tumor suppressor gene at human chromosome 18q21.1. Science 271: 350-353, 1996.

45. Le Clerc S, Limou S, Coulonges C, Carpentier W, Dina C, Taing L, Delaneau O, Labib T, Sladek R, Deveau C, et al; ANRS Genomic Group: Genomewide association study of a rapid progression cohort identifies new susceptibility alleles for AIDS (ANRS Genomewide Association Study 03). J Infect Dis 200: 1194-1201, 2009.

46. Michaud-Levesque J and Richard S: Thrombospondin-1 is a transcriptional repression target of PRMT6. J Biol Chem 284: 21338-21346, 2009.

47. Jegga AG, Gowrisankar S, Chen J and Aronow BJ: PolyDoms: A whole genome database for the identification of non-synonymous coding SNPs with the potential to impact disease. Nucleic Acids Res 35 (Database): D700-D706, 2007.

48. Yue $\mathrm{P}$ and Moult $\mathrm{J}$ : Identification and analysis of deleterious human SNPs. J Mol Biol 356: 1263-1274, 2006.

49. Bonasio R, Lecona E and Reinberg D: MBT domain proteins in development and disease. Semin Cell Dev Biol 21: 221-230, 2010

50. Ip WK, Lai PB, Wong NL, Sy SM, Beheshti B, Squire JA and Wong N: Identification of PEG10 as a progression related biomarker for hepatocellular carcinoma. Cancer Lett 250: 284-291, 2007.

51. Chen J, Zheng H, Bei JX, et al: Genetic structure of the Han Chinese population revealed by genome-wide SNP variation. Am J Hum Genet 85: 775-785, 2009.

52. Wellcome Trust Case Control Consortium: Genome-wide association study of 14,000 cases of seven common diseases and 3,000 shared controls. Nature 447: 661-678, 2007.

53. Duggal P, Gillanders EM, Holmes TN and Bailey-Wilson JE: Establishing an adjusted p-value threshold to control the family-wide type 1 error in genome wide association studies. BMC Genomics 9: 516, 2008

54. Teleman AA, Chen YW and Cohen SM: Drosophila Melted modulates FOXO and TOR activity. Dev Cell 9: 271-281, 2005.

55. Sjöblom T, Jones S, Wood LD, et al: The consensus coding sequences of human breast and colorectal cancers. Science 314: 268-274, 2006 
56. Jensen LJ, Kuhn M, Stark M, Chaffron S, Creevey C, Muller J, Doerks T, Julien P, Roth A, Simonovic M, et al: STRING 8 - a global view on proteins and their functional interactions in 630 organisms. Nucleic Acids Res 37 (Database): D412-D416, 2009.

57. Matys V, Fricke E, Geffers R, Gössling E, Haubrock M, Hehl R, Hornischer K, Karas D, Kel AE, Kel-Margoulis OV, et al: TRANSFAC: Transcriptional regulation, from patterns to profiles. Nucleic Acids Res 31: 374-378, 2003.

58. Matsushima-Nishiwaki R, Shidoji Y, Nishiwaki S, Yamada T, Moriwaki $\mathrm{H}$ and Muto Y: Aberrant metabolism of retinoid X receptor proteins in human hepatocellular carcinoma. Mol Cell Endocrinol 121: 179-190, 1996.
59. Zender L, Villanueva A, Tovar V, Sia D, Chiang DY and Llovet JM: Cancer gene discovery in hepatocellular carcinoma. J Hepatol 52: 921-929, 2010.

60. van Hengel J, D'Hooge P, Hooghe B, Wu X, Libbrecht L, De Vos R, Quondamatteo F, Klempt M, Brakebusch C and van Roy F: Continuous cell injury promotes hepatic tumorigenesis in cdc42-deficient mouse liver. Gastroenterology 134: 781-792, 2008. 